\title{
FINANCEIRIZAÇÃO E ESTRATÉGIA: NARRATIVA E NÚMEROS
}

Financialization \& strategy: narrative and numbers

FROUD, J.; JOHAL, S. et. al., Financialization \& strategy: narrative and numbers. Routledge: Oxford, 2006.

Patricia Mari Matsuda'

A obra analisada utiliza métodos de pesquisa quantitativos e qualitativos para avaliar a dinâmica das mudanças socioculturais das firmas gigantes listadas na S\&P 500 e na FTSE 100, grupo das empresas com maior valor de mercado dos Estados Unidos e do Reino Unido. O periodo de análise vai da década de 90 até o início dos anos 2000. Ela é separada em três estudos de caso aplicados em três grandes companhias, a General Eletric, a Ford e a GlaxoSmithKline. Os autores realizaram estudos empíricos de modelos moldados na descrição de casos. Estudiosos procuram demonstrar como essas firmas gigantes respondem à pressão do mercado de capitais através de três casos detalhados das três empresas.

Os autores fazem parte do grupo de estudos denominado CRESC Centre for Research on Socio-Cultural Change, que realizam abordagens interdisciplinares das ciências sociais e das humanidades em geral. Fligstein (1990) e Granovetter (2007) seguem a mesma linha do grupo de estudos CRESC ao destacar a importância das relações sociais na economia. Fligstein (1990) também separa o seu estudo em eras: de produção, marketing e financeira, sendo que essa última se destaca nessa presente análise.

O presente livro é indicado como uma referência para aqueles que se dedicam a compreensão dos estudos do mercado de capitais na estratégia corporativa. Algumas obras são relacionadas ao analisar a história, a cultura e os valores em uma só empresa, como, por exemplo, no livro "Privatizing

\footnotetext{
1 Doutora pelo Programa de Pós Graduação em Engenharia de Produção da Universidade Federal de São Carlos. Professora do curso de Administração no Centro Universitário da FEI, São Bernardo do Campo, Brasil. E-mail: patymaryeu@gmail.com.
} 
Poland" da autora Dunn (2004) traz uma abordagem dos processos relacionados à privatização da Polônia que faz uma pesquisa empírica que analisa o estudo de caso da privatização da empresa Alima, conduzido por Janusz Lewandowski, ministro da privatização da Polônia. Essa mudança de propriedade de estatal para privada acaba por mudar o dia a dia da empresa, como também suas relações de trabalho. Trata-se, portanto, de um estudo sociológico do impacto da mudança de propriedade, saindo das mãos do governo para uma empresa privada americana, a Gerber.

Outro caso relacionado seria o da empresa "Lenovo", estudada pelos autores Useem e Liang (2011) que discutem a união de uma empresa americana com uma chinesa e a formação da Lenovo de fabricante de computadores pessoais, se apresentam as proximidades e as transparências por intermédio das práticas de Governança Corporativa. Autores procuram destacar as lutas internas na reconstrução do poder da nova companhia. Dunn (2004), Useem e Liang (2011) e a presente obra analisada apresentam resultados da reestruturação das empresas do século XXI, e nessa mudança, a "grande empresa" foi transformada e eles advogam que por meio dessa transformação chamada financeirização, a empresa é controlada pelos acionistas através da governança corporativa, dessa forma, o mercado de capitais remodelou as empresas. Nesse momento os números e as performances são mais importantes que as próprias companhias no sentido que as mesmas só procuram trazer números aos acionistas, não se preocupando com a produtividade.

Dunn (2004), Useem e Liang (2011) e a presente obra trazem à tona casos de empresas que sofreram reestruturação através da financeirização em âmbito mundial e discutem o tema do processo de crescimento das empresas através de números. Destacar-se-á nesta obra a originalidade em seu texto e sua contribuição para os estudos em Sociologia Econômica ao debater questões acerca de empresas que se financeirizam, remodelando-as. Autores descrevem que ao comparar o crescimento das empresas em relação à economia nacional, os resultados mostram que as grandes firmas não 
crescem mais rápido que o PIB, enquanto os salários dos CEOs crescem com muito mais velocidade.

Em suma, são descritas algumas de suas principais análises, dos anos 80 aos 2000, nas maiores firmas dos Estados Unidos e do Reino Unido, no livro aparecem em forma de gráficos. (1) Uma comparação entre o salário do CEO e o salário do trabalhador para valores reais pagos, (2) A discrepância entre o salário dos CEOs e dos trabalhadores vem aumentando ao longo dos anos; (3) Quanto maiores forem as empresas, maiores serão os salários dos CEOs; (4) Ocorreu uma valorização das ações frente ao PIB (bull Market anos 90); (5) As organizações familiares diminuíram (households); (6) O ativo financeiro (moeda) cresceu ao longo dos anos mais do que o ativo fixo (poupável) nas empresas; (7) As dividas aumentaram; (8) O lucro acumulado foi ao longo dos anos menor; (9) Ocorreu um aumento do número de empregos temporários.

Sobre a financeirização e a performance corporativa, existia muita discrepância entre narrativa e números. Haviam estratégias sim, como por exemplo, movimentos de fusão, o gerenciamento baseado em valor para o acionista realizado por empresas de consultorias (GRUN, 2004) e a alavancagem financeira (USEEM, 1993), mas poucas mudanças nas firmas para atingir números e resultados. Esta é uma evidência de que as maiores firmas são frequentemente ineficientes em criar valor através da estratégia de intervenção para melhorar os números. Sendo assim, de acordo com os autores a estratégia é caracterizada pela mediocridade ao invés de sucesso.

Ressalta-se que quando autores dizem “(...) exploratory singlecompany case studies as well as generalization about the value creation records of the two groups of giant companies in the UK FTSE 100 and the US S\&P 500 over the past twenty years" (p.5) eles se referem às empresas que possuem valor de suas ações representativas entre as 500 mais altas da Bolsa de Valores de Nova York - NYSE e Bolsa de Valores de Londres - FTSE. Gerentes fazem muitos movimentos, mas em poucos niveis para entregar resultados financeiros, o problema era entregar números por parte dos 
CEOs. É importante ressaltar que nos anos 90 ocorreram muitas fraudes por parte dos CEOs na entrega de números, uma vez que seus salários e bônus dependiam da performance da empresa. Na década de 90, iniciou-se um forte movimento da Governança Corporativa para proteger as empresas de fraudes.

Nos estudos de caso das três empresas reunidas, foi feito uma análise de um periodo de 30 anos, autores separaram o livro em três partes e apresentam evidências de três empresas que não conseguem alinhar as narrativas com os números apresentados em seus indicadores de desempenho.

O estudo sobre a Glaxo, empresa da indústria farmacêutica, cobre um período de 30 anos e mostra um percurso do sucesso à decepção. A Indústria farmacêutica Glaxo era a mais bem-sucedida na Europa na década de 80, a líder do setor financeiro britânico. Ela enfrentou diversas dificuldades como críticas de investimentos em marketing e a expiração de patente de um dos seus principais produtos, o Zantac. Porém, uma década e duas fusões mais tarde culminou no fracasso da GlaxoSmithKline em 2000. No caso Ford, os estudiosos debatem sobre o valor do esforço e recompensa, apresentam a empresa automobilística como uma empresa que criou um modo de produção com seu nome no período, o fordismo. Mas eles também destacam as mudanças ocorridas nesse tipo de indústria, foram feitas considerações à história da ascensão, a indústria japonesa e a forte competição, além do ambiente desta indústria ser muito incerto aos investidores.

A Ford faz parte das três montadoras do ocidente - Ford, General Motors e Chrysler - as quais, nos anos 80 , foram derrotadas pelos japoneses na produção enxuta, o que provocou desproporção entre esforço e recompensa financeira. Dado que os retornos dos acionistas nas fábricas de automóveis ficam atrás das industriais. Porém, uma saída foi criar o sistema leasing: sistema de bens e serviços, como finanças, seguro e manutenção. De tal modo, que o sistema financeiro, de serviços oferecidos nesta área, passou a ter retornos superiores aos industriais. 
No terceiro estudo de caso, os autores destacam a empresa General Electric como uma empresa de sucesso. Procura-se apresentar quais seriam as condições para que esta empresa fosse um caso de sucesso nas décadas de 80 e 90 nos EUA. Um ponto importante levantado seria de que a GE não é um conglomerado, ela tem diversificação financeira, sendo o segmento de energia e o de seguro os mais importantes.

Com a entrada do novo CEO Jeff Immelt em 2001, criou-se uma nova empresa. Ele conseguiu manter a empresa no caminho de sucesso, apresentou um plano com a Governança Corporativa clara, divulgou contas da empresa, comprou aquisições industriais. Enfim, apresentou uma nova direção, revendo a carteira de participações da empresa. Além disso, o montante da GE capital foi útil, mas os ganhos da GE industrial foram cruciais para ajudar a corroborar a narrativa da empresa, deste modo, resultou-se em maiores lucros.

Nos três casos, se procurou manter as ações das companhias em alta. Mas as narrativas às vezes não condiziam com os resultados da empresa.

O caso da GlaxoSmithKline seria um caso de sucesso com os movimentos de fusões e aquisições, mas que não conseguiu segurar o preço de suas ações. Já o segundo caso, da Ford, que foi um caso de fracasso e sucesso, pois conseguiu sobreviver graças ao alinhamento da indústria automobilística com as empresas de serviços financeiros, que oferecem serviços de leasing dos carros. E por fim, o caso da General Eletric, um episódio de sucesso após sucesso, mesmo após a troca de direção, a empresa se mantém em conglomerados transparentes e sólidos.

Os três estudos de caso em âmbito mundial trazem à tona casos de empresas que sofreram transformação através da financeirização. Autores do livro discutem o impacto do mercado de capitais sobre empresas gigantes dos Estados Unidos e do Reino Unido desde os anos 80. E chegam à conclusão de que a pressão pelos acionistas nas grandes empresas não levou a uma significativa melhora no grupo dos gigantes. 
Os dados apresentados no Financialization and strategy: narrative and numbers, podem ser utilizados como um check list, para estudiosos da área, para verificar através da literatura internacional o que autores consideram como característica de uma empresa financeirizada. Assim como verificar em outras empresas o seu grau de financeirização.

Outros autores relacionados ao estudo da Sociologia econômica tratam sobre as relações sociais na economia. No terceiro estudo de caso da Glaxo, se analisa a troca de presidência e seu impacto na companhia de forma positiva ao conseguir seguir com os mesmos projetos existentes. Da mesma forma, o autor Granovetter (2007) decorre sobre as relações sociais, que são importantes para esse estudo, pois a ação econômica está imersa nas estruturas sociais, por conseguinte, as instituições são afetadas pelas relações sociais presentes.

Ainda, é de grande valia discutir as mudanças de concepção de controle, observadas por Fligstein (1990), visto que o autor ressalta que as empresas mudam de concepção dominante de acordo com as legislações impostas e com vistas à sua sobrevivência. Do qual foram observadas mudanças caminhando para a financeirização das mesmas nos três casos de sucesso e fracasso. As mesmas tiveram mudança no alto escalão e as mudanças impostas afetaram toda a estrutura organizacional. Assim como, Zilbovicius (1999) segue a mesma linha, para entender a modificação e a financeirização da empresa, fazem-se necessários os argumentos de Zilbovicius (1999), a respeito das empresas institucionalizadas e como elas sobrevivem através da legitimidade. O autor ressalta que existe um maior desejo de mudança, do que mudanças efetivas nas organizações. Zilbovicius (1999) ressalta que é preciso compreender o modelo como um desenvolvimento histórico.

Por fim, esse livro é importante aos estudiosos da Sociologia econômica, pois traz uma contribuição ao debater as mudanças da financerização para as empresas que a adotam, remodelando-as.

Autores declaram que a financeirização cria problemas para os gerentes corporativos porque a estratégia de uma empresa gigante não é 
apenas sobre movimentos e resultados no mercado de capitais, mas também consiste em entrega de uma narrativa estratégica que é, às vezes, corroborada por resultados financeiros.

A maioria das grandes empresas precisa de caixa e lucros para distribuir aos acionistas e para suportar o preço da ação. Neste contexto, os autores propõem nessa obra um novo método de análise das grandes empresas do século XXI que envolve jogar um contra o outro: as narrativas e os números - para explorar a corroboração e a discrepância entre os dois registros de narrativa e números.

\section{Referência}

DUNN, E. C. Privatizing Poland: Baby Food, Big Business, and the Remaking of Labor. New York: Cornell University Press. Culture and Society after Socialism, 2004

FLIGSTEIN, N. The transformation of corporate control. Cambridge, Mass.: Harvard University Press, 1990.

FROUD, J.; JOHAL, S. et. al., Financialization \& strategy: narrative and numbers. Routledge: Oxford, 2006.

GRANOVETTER, M., Ação econômica e estrutura social: o problema da imersão. FÓRUM- SOCIOLOGIA ECONÔMICA: Stanford University RAEeletrônica, v. 6, n. 1, Art. 9, jan./jun. 2007.

GRUN, R. Corporate governance in Brazil: From a "neo-liberal zealot" issue to a "practical consultant" business, conderence paper given at SASE conference, 8-11 July 2004, Washington, DC, 2004.

USEEM, M. Executive defense: Shareholder Power and Corporate Reorganization, Cambridge, Mass.: Harvard University Press, 1993.

USEEM, M.; LIANG, N. Globalizando o conselho de administração: lições da empresa chinesa Lenovo. . Capítulo 3, 107 - 155. In: DONADONE, J. C.; JARDIM, M. A. C. As centralidades e as fronteiras das empresas do século 21. 1 ed. Bauru: Edusc, 2011

ZILBOVICIUS, M. Modelos para a Produção, Produção de Modelos: gênese, lógica e difusão do modelo japonês de organização da produção. São Paulo: Editora FAPESP / AnnaBlume, 1999. 